\title{
East Antarctic sea ice in spring: spectral albedo of snow, nilas, frost flowers and slush, and light-absorbing impurities in snow
}

\author{
Maria C. ZATKO, Stephen G. WARREN \\ Department of Atmospheric Sciences, University of Washington, Seattle, WA, USA \\ E-mail: mzatko@uw.edu
}

\begin{abstract}
Spectral albedos of open water, nilas, nilas with frost flowers, slush, and first-year ice with both thin and thick snow cover were measured in the East Antarctic sea-ice zone during the Sea Ice Physics and Ecosystems eXperiment II (SIPEX II) from September to November 2012, near 65 ${ }^{\circ}$ S, $120^{\circ} \mathrm{E}$. Albedo was measured across the ultraviolet (UV), visible and near-infrared (nIR) wavelengths, augmenting a dataset from prior Antarctic expeditions with spectral coverage extended to longer wavelengths, and with measurement of slush and frost flowers, which had not been encountered on the prior expeditions. At visible and UV wavelengths, the albedo depends on the thickness of snow or ice; in the $n I R$ the albedo is determined by the specific surface area. The growth of frost flowers causes the nilas albedo to increase by $0.2-0.3$ in the UV and visible wavelengths. The spectral albedos are integrated over wavelength to obtain broadband albedos for wavelength bands commonly used in climate models. The albedo spectrum for deep snow on first-year sea ice shows no evidence of lightabsorbing particulate impurities (LAI), such as black carbon (BC) or organics, which is consistent with the extremely small quantities of LAI found by filtering snow meltwater. Estimated BC mixing ratios were in the range 0.1-0.5 $\mathrm{ng}$ of carbon per gram of snow.
\end{abstract}

KEYWORDS: Antarctic glaciology, sea ice, snow, snow chemistry, snow physics

\section{INTRODUCTION}

The solar energy budget of the Antarctic Ocean, which is responsible for the seasonal timing of growth and decay of sea ice, is determined by both surface albedo and cloud thickness (Fitzpatrick and Warren, 2007). Antarctic sea ice may be an important player in future climate change (Rind and others, 1995; Holland and Bitz, 2003), and knowledge of its albedo is needed for accurate simulations of climate (Meehl and Washington, 1990; Rind and others, 1997; Hall, 2004). The input of solar energy to the ocean is limited by reflection of sunlight by the snow/ice system. The large-scale flow of the Antarctic sea ice is generally divergent, opening leads of open water that can refreeze, so the sea-ice zone in spring exhibits a variety of ice types of varying thickness and snow cover, with a corresponding variety of albedo values (Brandt and others, 2005).

For bare ice, particularly young 'nilas' (a thin uniform sheet formed by freezing in calm water), the albedo increases as the ice thickens. Later, after snow falls onto the young ice, its albedo is determined mainly by snow thickness and snow grain size. Before it is covered with snow, thin dark nilas exposed to cold air, particularly on clear nights, can become decorated by 'frost flowers' (Perovich and Richter-Menge, 1994; Style and Worster, 2009); the resulting enhancement of albedo is similar to that caused by a thin snow layer. Slush can form when the wind blows snow into new leads of open water, resulting in an albedo intermediate between water and snow.

Light-absorbing impurities (LAI) can cause a reduction of albedo at wavelengths where the albedo is high; this is most notable for snow at visible and ultraviolet (UV) wavelengths (Warren and Wiscombe, 1980). There are several types of LAI that may be present in snow. Per unit mass, black carbon (BC) is the most absorptive material. Non-BC species include brown (organic) carbon, mineral dust and humic-like substances (HULIS) (Hoffer and others, 2006; Doherty and others, 2010; France and others, 2012; Voisin and others, 2012). The amounts of these impurities are sufficient to reduce surface albedo by a few percent in the Arctic (Clarke and Noone, 1985; Doherty and others, 2010), but in the interior of Antarctica the amounts are far too small to affect the albedo (Warren and Clarke, 1990). A global database of these impurities is being developed. Snow has previously been surveyed for LAI in the Arctic, in northern China, in Europe, in North America and on the Antarctic plateau, but not on Antarctic sea ice.

This paper reports on measurements of spectral albedo and LAI during the Sea Ice Physics and Ecosystems eXperiment II (SIPEX II) field campaign of the Australian National Antarctic Research Expeditions (ANARE), from 16 September to 16 November 2012. This project continues a collaboration between the University of Washington and the Australian Antarctic Division (AAD), which involved prior expeditions to the East Antarctic sea-ice zone in 1988, 1996 and 2000 (Allison and others, 1993; Warren and others, 1993; Fitzpatrick and others, 2004; Brandt and others, 2005; Fitzpatrick and Warren, 2005, 2007). The icebreaking ship Aurora Australis traveled from Hobart, Tasmania, toward the coast of East Antarctica near Casey Station (Fig. 1). For most of the time that the ship was in the sea-ice zone, it was located near $65^{\circ} \mathrm{S}, 120^{\circ} \mathrm{E}$.

\section{CONDITIONS DURING SIPEX II}

The Aurora Australis was in the sea-ice zone from 21 September to 12 November, stopping eight times at ice stations' where researchers could exit the ship to conduct measurements on and near a floe of thick first-year ice. Synoptic storms were prevalent throughout the voyage, causing difficulty in finding large floes for ice stations until 


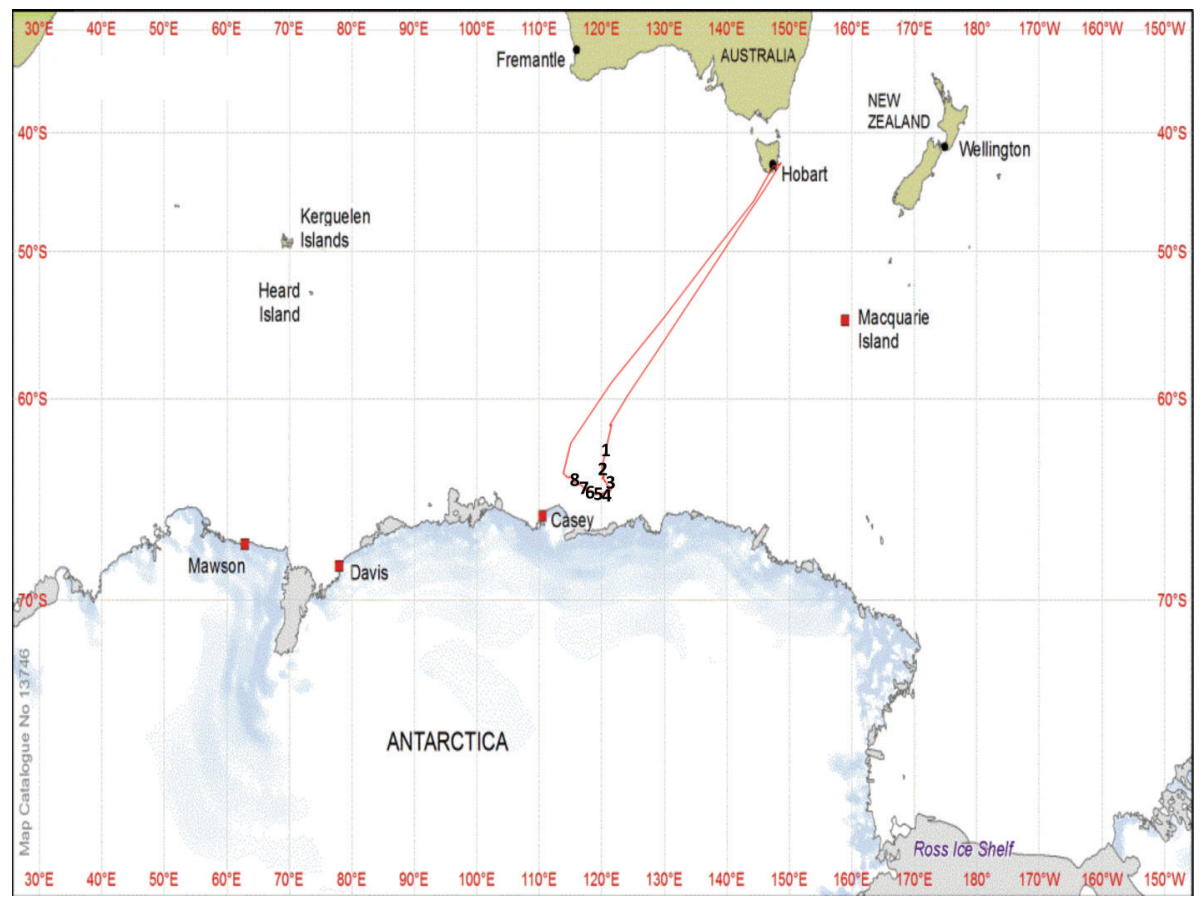

Fig. 1. The track of the Aurora Australis icebreaker during SIPEX II from 16 September to 16 November 2012. The approximate location of each ice station is provided. This map is courtesy of the Australian Antarctic Division.

the ship had traveled significantly into the sea-ice pack away from the marginal ice zone. Both the first-year sea ice and its snow cover were anomalously thick during the field campaign, in comparison both to the SIPEX I voyage in spring 2007 (Toyota and others, 2011) and to long-term averages (Massom and others, 2001). For the period 19792012, the all-time record maximum areal extent of Antarctic sea ice $\left(19.44 \times 10^{6} \mathrm{~km}^{2}\right)$ was reached during September 2012 (NSIDC, 2012). During the voyage the snow thickness on first-year sea ice ranged from 60 to $150 \mathrm{~cm}$, and the thickness of first-year sea ice ranged from 1 to $5 \mathrm{~m}$.

\section{ALBEDO MEASUREMENTS}

During our prior expeditions, spectral radiometers spanning wavelengths $(\lambda)$ from 300 to $1060 \mathrm{~nm}$ were used. Calculation of broadband albedo therefore required assumptions to be made about the behavior of the albedo spectrum at the wavelengths not measured, $1060-2500 \mathrm{~nm}$. Table 1 provides broadband albedos from these previous studies (tables 1 and 3 in Brandt and others, 2005) along with the broadband albedos calculated from spectral albedos measured during SIPEX II. The total-solar broadband albedos span a wide range, from 0.06 for open water to 0.87 for thick snowcovered ice under cloud.

\subsection{Instrument and platforms}

During SIPEX II the albedo measurements were made using a portable scanning spectral radiometer manufactured by Analytical Spectral Devices, Inc. (Kindel and others, 2001). The instrument (ASD) employs three separate grating radiometers that simultaneously measure radiance across three wavelength regions covering the range $350-2500 \mathrm{~nm}$, with spectral resolution $3-10 \mathrm{~nm}$, and can average 100 scans in $10 \mathrm{~s}$. The ASD is designed specifically to cover the solar spectrum, and has order-blocking and cut-off filters to ensure uncontaminated spectra. A 'cosine collector' consisting of a
Spectralon diffuser-plate receptor is used to measure downwelling and upwelling incident flux. The ASD and its computer are both battery-powered and housed in separate insulated boxes. The electronics are kept warm by selfheating supplemented by battery-powered heaters.

The ASD is contained in a sled and is connected by a fiberoptic cable to the cosine collector located on a $3 \mathrm{~m}$ metal rod, allowing the cosine collector to be projected out over thin ice some distance from the ASD. The rod contains a counterweight on the end closest to the ASD, and a tripod is used to steady the rod. Bubble levels on both inboard and outboard ends of the rod facilitate leveling of the diffuser plate. The diffuser plate is rotated nine times, alternately up toward the sky and down toward the surface, to measure five downwelling and four upwelling spectra. Because the downwelling radiation flux may change slightly with time as cloud transmittance changes, two upwelling spectra bracketing a downwelling spectrum are interpolated to the time the downwelling spectrum was made; then the interpolated upwelling flux is divided by the downwelling flux to obtain the albedo. Four albedo spectra are thus obtained, which usually would be nearly identical; they are then averaged to form a representative albedo spectrum for that surface type. Figure 2 shows photographs of the ASD in use.

For albedo measurements of snow-covered first-year sea ice, the tripod legs were pushed into the snow so that the diffuser plate was suspended $70 \mathrm{~cm}$ above the surface. All other ice types were too thin to support our weight, so we operated either from an inflatable rubber boat (IRB) or from the edge of a thick ice floe. To measure thin sea ice in a narrow lead, we dug away the snow covering the thick sea ice and then placed the sled and tripod down onto the bare ice surface adjacent to the lead; the cosine collector was then extended out over the thin ice. If the tripod had instead rested on the snow, the cosine collector would have been considerably higher than the desired $70 \mathrm{~cm}$ height above the surface to be measured. When using the IRB, the sled and 
Table 1. Broadband albedos computed from spectral albedos measured during SIPEX II using Eqn (2) for three wavelength intervals and for two sky conditions. Springtime broadband albedos from tables 1 and 3 in Brandt and others (2005) are included for comparison

\begin{tabular}{|c|c|c|c|c|c|c|c|}
\hline \multirow[t]{2}{*}{ Ice type } & \multirow[t]{2}{*}{ Date } & \multicolumn{2}{|c|}{ 290-3000 nm } & \multicolumn{2}{|c|}{$290-700 \mathrm{~nm}$} & \multicolumn{2}{|c|}{$700-3000 \mathrm{~nm}$} \\
\hline & & Clear & Cloudy & Clear & Cloudy & Clear & Cloudy \\
\hline \multirow[t]{2}{*}{ Open water } & 14 Oct 2012 & 0.06 & 0.06 & 0.07 & 0.07 & 0.06 & 0.06 \\
\hline & Brandt and others (2005) & 0.07 & 0.07 & 0.07 & 0.07 & 0.06 & 0.06 \\
\hline \multicolumn{8}{|l|}{ Grease ice } \\
\hline \multicolumn{8}{|l|}{ Nilas } \\
\hline $0.5-0.8 \mathrm{~cm}$ & 6 Oct 2012 & 0.13 & 0.14 & 0.15 & 0.15 & 0.12 & 0.13 \\
\hline $3-6 \mathrm{~cm}$ & 13 Oct 2012 & 0.13 & 0.14 & 0.15 & 0.15 & 0.12 & 0.12 \\
\hline$<10 \mathrm{~cm}$ & Brandt and others (2005) & 0.14 & 0.16 & 0.18 & 0.18 & 0.11 & 0.12 \\
\hline$<10 \mathrm{~cm}, 3 \mathrm{~cm}$ snow & Brandt and others (2005) & 0.42 & 0.45 & 0.50 & 0.50 & 0.33 & 0.36 \\
\hline \multicolumn{8}{|l|}{ Nilas with frost flowers } \\
\hline \multicolumn{8}{|l|}{ Young grey ice } \\
\hline $10-15 \mathrm{~cm}$ & Brandt and others (2005) & 0.25 & 0.27 & 0.30 & 0.30 & 0.19 & 0.21 \\
\hline \multicolumn{8}{|l|}{ Slush } \\
\hline $5 \mathrm{~cm}$ & 9 Oct 2012 & 0.30 & 0.35 & 0.46 & 0.47 & 0.16 & 0.19 \\
\hline $10 \mathrm{~cm}$ & 14 Oct 2012 & 0.41 & 0.46 & 0.59 & 0.59 & 0.25 & 0.29 \\
\hline $10 \mathrm{~cm}$ & 20 Oct 2012 & 0.39 & 0.45 & 0.60 & 0.61 & 0.20 & 0.24 \\
\hline $18 \mathrm{~cm}$ & 23 Oct 2012 & 0.51 & 0.59 & 0.78 & 0.78 & 0.28 & 0.33 \\
\hline \multicolumn{8}{|l|}{ First-year ice $(<70 \mathrm{~cm})$} \\
\hline$<3 \mathrm{~cm}$ snow & Brandt and others (2005) & 0.74 & 0.79 & 0.85 & 0.85 & 0.60 & 0.66 \\
\hline $2-4 \mathrm{~cm}$ snow & 14 Oct 2012 & 0.69 & 0.74 & 0.80 & 0.80 & 0.25 & 0.29 \\
\hline \multicolumn{8}{|l|}{ First-year ice $(>70 \mathrm{~cm})$} \\
\hline No snow & Brandt and others (2005) & 0.49 & 0.54 & 0.67 & 0.67 & 0.29 & 0.31 \\
\hline$<3 \mathrm{~cm}$ snow & Brandt and others (2005) & 0.81 & 0.87 & 0.94 & 0.94 & 0.65 & 0.72 \\
\hline $45 \mathrm{~cm}+0.2 \mathrm{~cm}$ crust & 8 Oct 2012 & 0.80 & 0.86 & 0.98 & 0.98 & 0.62 & 0.70 \\
\hline \multicolumn{8}{|l|}{ Snow on slush } \\
\hline $2 \mathrm{~cm}$ snow, $3 \mathrm{~cm}$ slush, $12 \mathrm{~cm}$ ice & 2 Nov 2012 & 0.75 & 0.80 & 0.87 & 0.87 & 0.65 & 0.72 \\
\hline $0.5 \mathrm{~cm}$ snow, $10 \mathrm{~cm}$ slush, $16 \mathrm{~cm}$ ice & 2 Nov 2012 & 0.59 & 0.63 & 0.68 & 0.68 & 0.51 & 0.56 \\
\hline
\end{tabular}

tripod rested on the IRB base while the rod and cosine collector extended over the side of the IRB.

The choice of $70 \mathrm{~cm}$ height for the diffuser plate is a compromise between two conflicting considerations. The diffuser plate receives radiation from all angles in a hemisphere, so when looking down at a narrow lead it receives radiation reflected not only from the target ice, but also from the snow walls of the lead. Moving the diffuser plate down closer to the surface reduces this source of error but also blocks some of the incident sunlight that would otherwise reach the surface. For diffuse incidence (under cloud), geometric analysis by Brandt and others (2011) showed that a shadowing correction of $1.7 \%$ was needed if the cosine collector was positioned $70 \mathrm{~cm}$ above the surface; a larger and more uncertain correction would be applicable for a cosine collector closer to the surface. The height of $70 \mathrm{~cm}$ was used for all our measurements, so our raw albedos measured under overcast cloud were all multiplied by the factor 1.017 for the plots of albedo shown in this paper.

Because the cosine collector receives radiation from all directions within a hemisphere, we attempted to position the cosine collector horizontally as far as possible from the edge of the snow-covered first-year sea ice, and the edge of the $I R B$, thus minimizing the influence of these surfaces on our reported albedos (see Section 3.2.2 for a computation of this error). Our most accurate measurements are made under cloudy-sky conditions, because 'tilt errors' due to inaccurate leveling of the cosine collector were minimized. Under clear-sky conditions, we made measurements within 2 hours of solar noon to experience the maximum solar altitude, which likewise minimized the tilt errors. During clear-sky conditions, we also oriented the rod toward the azimuth of the Sun so that the surface we were observing would not be shadowed by the tripod, rod and diffuser plate.

Table 2 lists, for all our albedo measurements, the date, location, weather conditions, surface types, and position of the ASD with respect to the surface being measured. Multiple albedo spectra were measured for each surface type. If the spectra looked similar they were averaged together to create one albedo spectrum and one set of broadband albedos. Sometimes it was necessary to remove an albedo spectrum if the sky conditions were changing too rapidly or if there was an operational error.

\subsection{Spectral albedos}

The albedos of ice and snow are the result of scattering of light at air/ice and ice/water interfaces, and limited by absorption of photons passing through ice between the scattering interfaces. The scattering is nearly independent of 


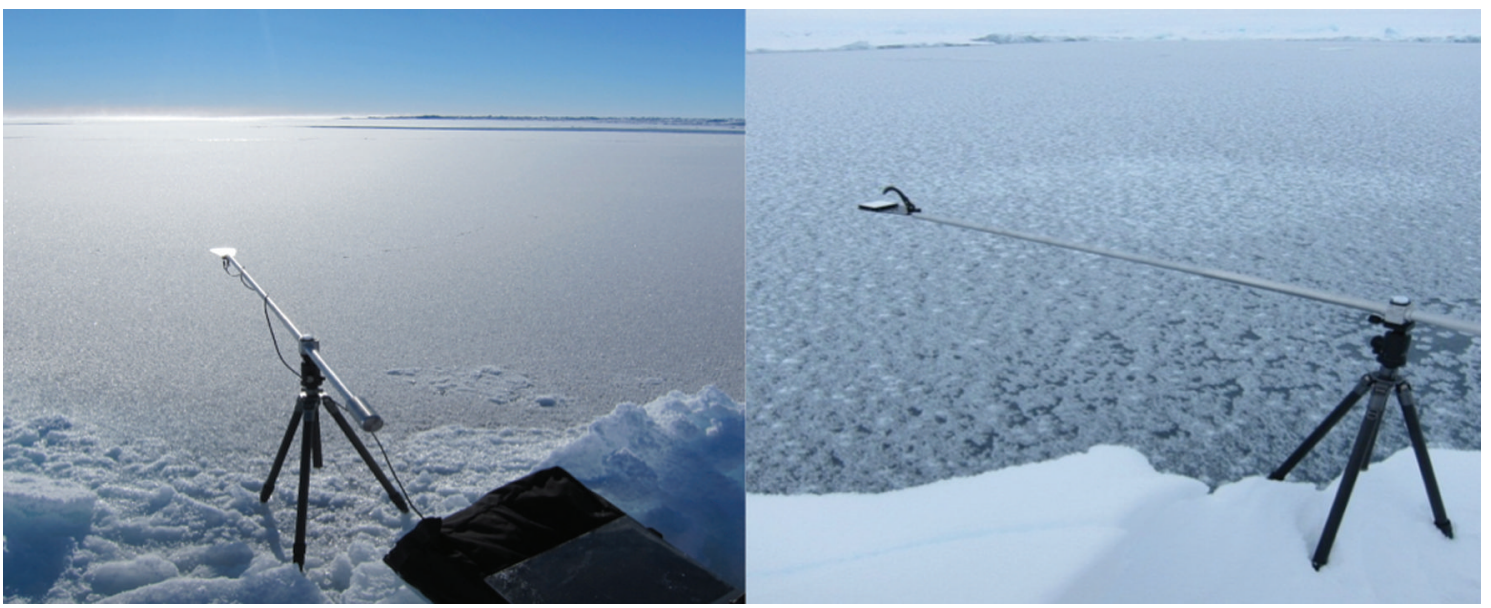

Fig. 2. Photographs showing ASD spectral radiometer. The ASD is contained in the sled (seen in left photograph) and is connected to a cosine collector on the far end of the metal rod by a fiber-optic cable. The rod contains a counterweight on the end closest to the ASD, and a tripod is used to steady the rod. The rod can be rotated to position the diffuser plate downward towards the ice surface and upwards towards the sky. The ASD is used here to measure the albedo of a dense frost-flower field covering nilas (left, 4 October 2012) and sparse frost-flower field covering nilas (right, 28 September 2012).

wavelength because snow grains, air bubbles and brine inclusions are all much larger than solar wavelengths, so the spectral variation of albedo is determined by the absorption spectrum of ice. The absorption coefficient varies by 7 orders of magnitude across the solar spectrum, from $\sim 10^{-3} \mathrm{~m}^{-1}$ at $\lambda=390 \mathrm{~nm}$ to $10^{4} \mathrm{~m}^{-1}$ at $\lambda=2 \mathrm{~m}$ (Warren and Brandt, 2008). The absorption length (the reciprocal of the linear absorption coefficient, and equal to the mean free path of a photon traveling through ice before absorption) exceeds $1.5 \mathrm{~km}$ in the near-UV but is as small as $0.1 \mathrm{~mm}$ at $\lambda=2 \mathrm{~m}$ in the near-infrared (nIR). Correspondingly, the albedo of deep snow approaches 1.0 in the UV and visible wavelengths, and $\sim 0.0$ at the centers of vibrational absorption bands at 1.5 and $2.0 \mathrm{~m}$.

Because scattering scales with the interfacial areas, and absorption scales with absorber mass, a good predictor of albedo is the ratio of air/ice interface area to ice mass, given the name 'specific surface area' (SSA; e.g. Matzl and Schneebeli, 2006, 2010). The SSA can be converted to an effective radius $r_{\mathrm{e}}$ (e.g. Grenfell and Warren, 1999):

$$
\mathrm{SSA}=\frac{3}{r_{\mathrm{e}} \rho_{\text {ice }}}
$$

where $\rho_{\text {ice }}$ is the density of pure ice, $917 \mathrm{~kg} \mathrm{~m}^{-3}$. Larger SSA

Table 2. Description of the ice stations where the albedos of surface types were measured during SIPEX II. The date, location, weather conditions, surface types, and position of the ASD radiometer with respect to the sea ice are provided. Measurements were made either from the edge of a floe or from an IRB. Ship time is coordinated universal time (UTC) +10 ; Sun time is UTC +8

\begin{tabular}{lll}
\hline Ice station & $\begin{array}{l}\text { Date }(2012), \\
\text { local Sun time }\end{array}$ & Location; ASD position
\end{tabular}

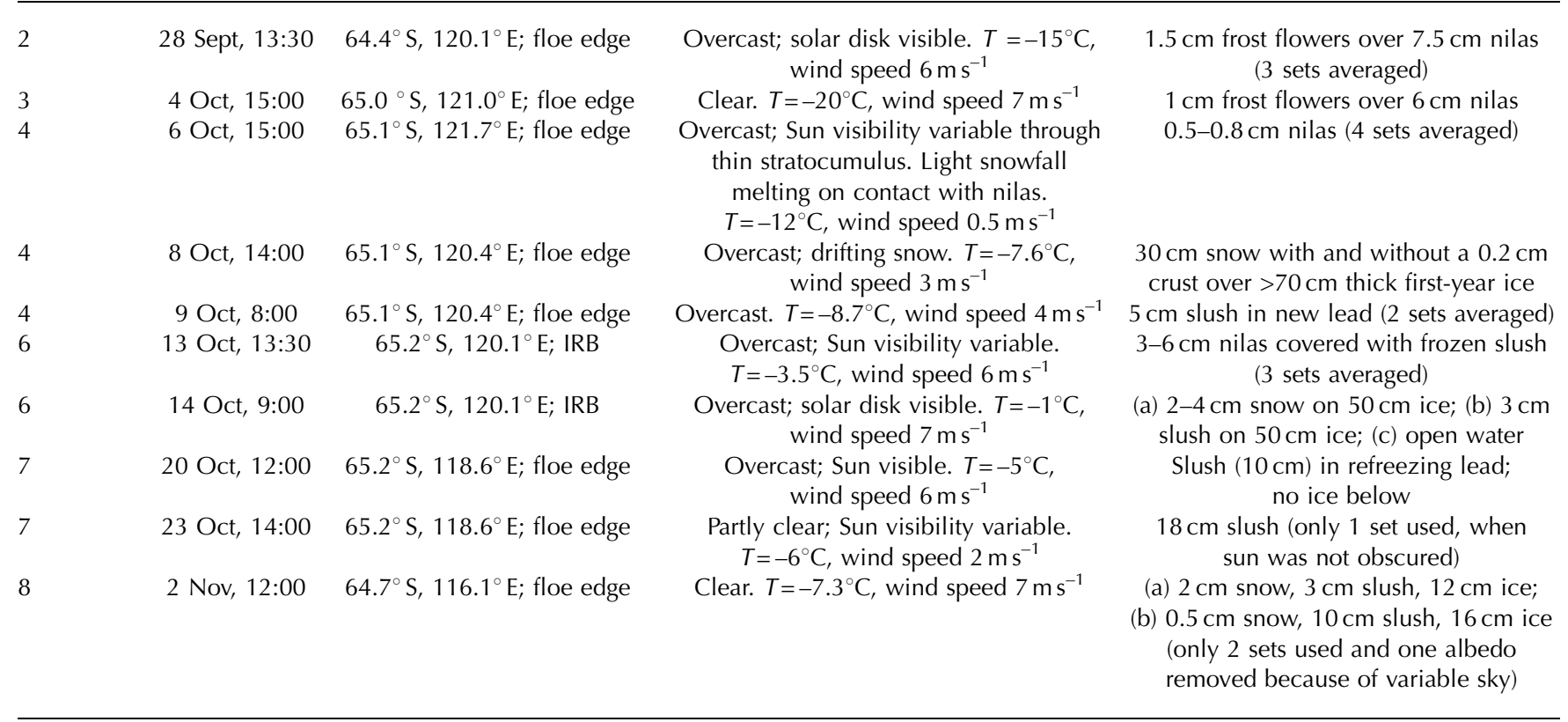




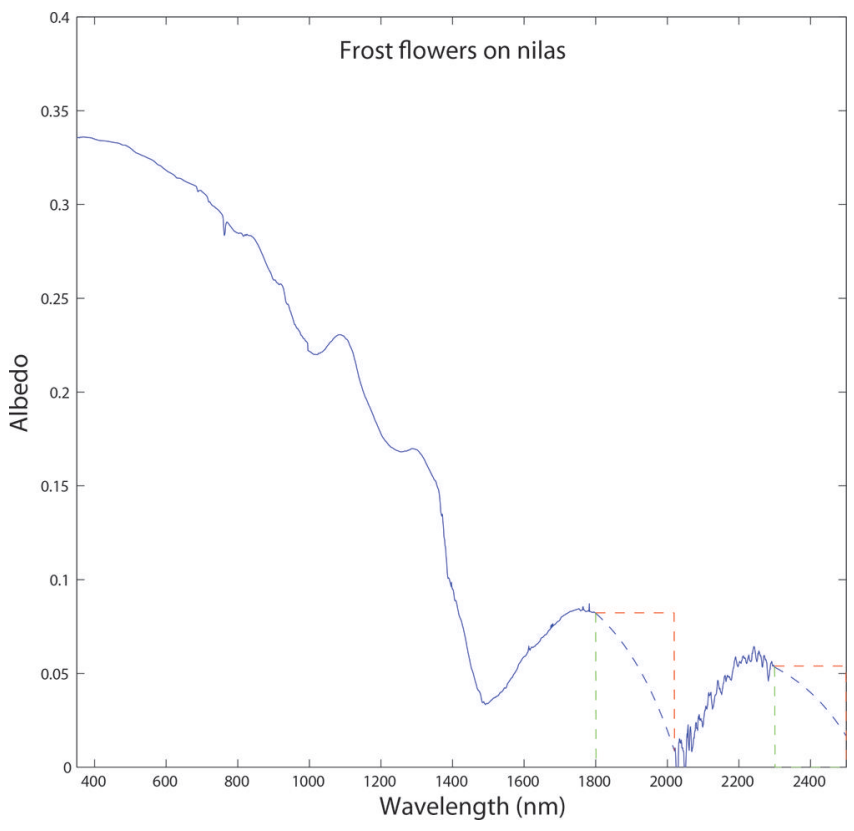

Fig. 3. Frost-flower albedo spectrum measured under overcast cloud on 28 September 2012 (blue line) along with the smoothing profile used during the calculation of broadband albedo (blue dashed line) and extreme upper and lower bounds (red and green dashed lines). See Section 3.2 for more detail.

(smaller $r_{\mathrm{e}}$ ) causes more scattering of radiation, decreasing the probability of absorption and increasing the albedo.

An example albedo spectrum is shown in Figure 3. The data measured in wavelength bands $1800-2100 \mathrm{~nm}$ and $2300-2500 \mathrm{~nm}$ are not plotted since they are so noisy as to be meaningless. At these wavelengths, both the upwelling and downwelling radiation fluxes are very small, close to the noise level of the instrument, particularly under cloud. Since clouds absorb nIR radiation at wavelengths where snow and ice are also absorptive (all three media consist of water and therefore exhibit the vibrational absorption bands of the water molecule), most of the radiation at those wavelengths is prevented from reaching the snow surface when clouds are present. We therefore smoothed the albedo values across these data gaps, paralleling the known behavior of snow albedo across these two wavelength domains (Grenfell and others, 1994), as indicated by the dashed blue lines in Figure 3. To determine whether the uncertainty in our smoothing procedure alters broadband albedos significantly, we calculated broadband albedos for every albedo spectrum, using the extreme upper and lower bounds shown in Figure 3. The largest change was in the broadband nIR albedo (700-3000 nm wavelength), which was altered by at most $2.3 \%$ when these limits were applied; the typical broadband nIR albedo change was $<1 \%$, and the total solar broadband albedo change was $<1 \%$. This small sensitivity to extreme assumptions is a consequence of the small fraction of incident solar energy in these two wavelength bands for which the smoothing was applied.

\subsubsection{Snow}

Snow-covered first-year ice was the most common ice type encountered in the East Antarctic sea-ice zone. Figure 4 shows albedo spectra for both thin $(2-4 \mathrm{~cm})$ and thick $(\sim 45 \mathrm{~cm})$ snow cover over first-year ice. The thick-snow albedo spectrum is similar to plots shown for clean snow on

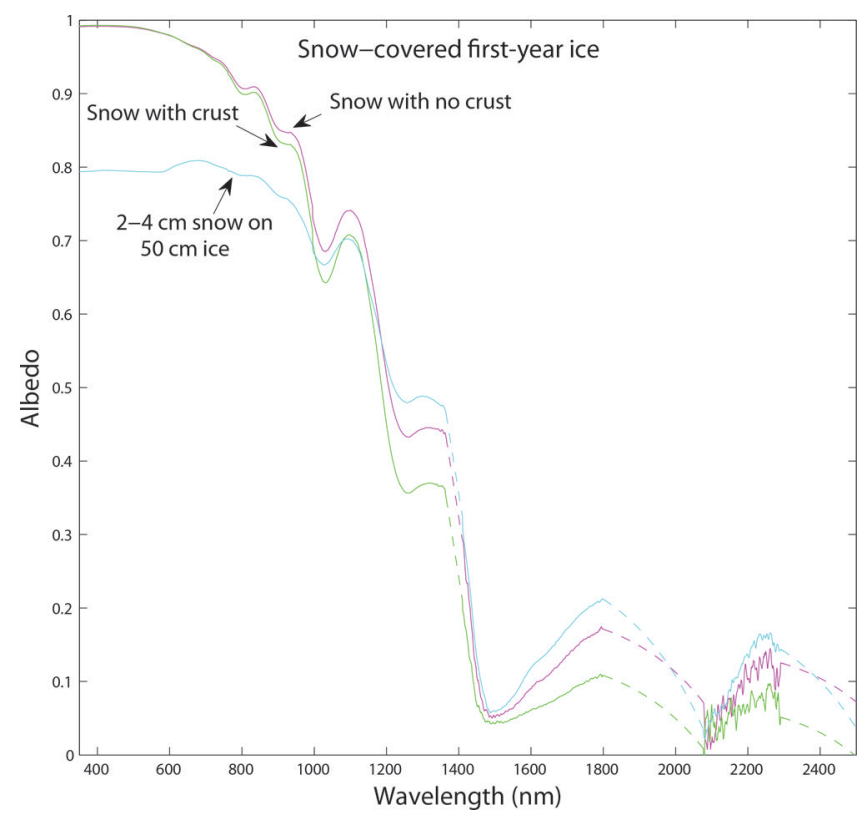

Fig. 4. Albedo spectra for thin $(2-4 \mathrm{~cm})$ and thick $(\sim 45 \mathrm{~cm})$ snow over first-year ice measured on 14 and 8 October, respectively. Data for wavelengths 1350-1400 nm, 1800-2100 nm and 2350$2500 \mathrm{~nm}$ (here and in Figs 6 and 9-11) are smoothed because of spectral noise resulting from low incident flux under cloudy sky conditions.

the Antarctic plateau at the South Pole by Grenfell and others (1994, fig. 4) and at Dome C by Hudson and others (2006, fig. 6). The two albedo spectra we measured on 8 October were both of $\sim 45 \mathrm{~cm}$ of snow on top of sea ice that was at least $1 \mathrm{~m}$ thick, but the snow surface in places was capped by a $0.2 \mathrm{~cm}$ crust, presumably from a melt-freeze cycle which would increase the grain sizes. We measured the albedo of both crusted and crust-free snow. In the UV and visible wavelength regions, the two spectra are identical because ice is so weakly absorptive here that the albedo is insensitive to grain size. In the nIR the crusted snow has lower albedo than the crust-free snow, as expected for larger $r_{\mathrm{e}}$.

The spectrum measured on 14 October was of $2-4 \mathrm{~cm}$ of snow over $50 \mathrm{~cm}$ of ice. It has lower albedo than the deep snow at visible wavelengths where the albedo is mainly determined by snow thickness, but in the nIR its albedo is higher than that of the deep snow. In the nIR, ice is more absorptive, just $2 \mathrm{~cm}$ of snow being enough to hide the underlying surface, so the albedo is determined just by the SSA of the surface snow layers, which apparently was larger on 14 October than on 8 October. Comparison to model calculations of Wiscombe and Warren (1980, fig. 8) suggests $r_{\mathrm{e}} \approx 100,140$ and $350 \mathrm{~m}$ for the thin snow, thick snow, and crust, respectively. A similar spectral pattern is seen when comparing the spectral albedo of snow (as in Fig. 4) to that of a cloud over a dark surface (fig. 7a of Wiscombe and others, 1984). The cloud has lower albedo than snow at visible wavelengths because it is optically thinner, but higher albedo than snow in the nIR because its particle sizes are smaller $\left(r_{\mathrm{e}} \approx 10 \mathrm{~m}\right)$.

\subsubsection{Nilas and open water}

Thin nilas (Fig. 5) is rather smooth and dark, barely distinguishable from open water. Figure 6 shows the albedo spectra for open water and for several nilas cases with different thickness. Some nilas albedo spectra from Brandt 


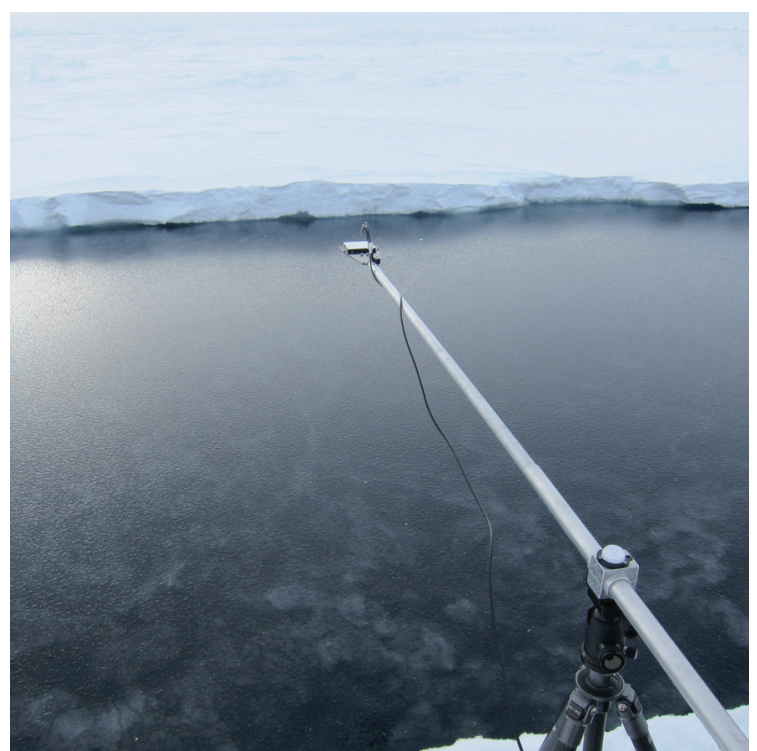

Fig. 5. Photograph of $0.5-0.8 \mathrm{~cm}$ thick nilas in a narrow lead on 6 October 2012. The albedo spectrum for this scene is shown in Figure 6.

and others (2005) are also plotted in Figure 6 for comparison; they are the curves that terminate at $1060 \mathrm{~nm}$ because of the limited spectral range of the radiometer used in the earlier expeditions. The albedo of open water, close to 0.07 at all wavelengths, is due almost entirely to the Fresnel reflection expected for diffuse incident radiation on water with a refractive index of 1.33 (Mironova, 1973). The albedo spectrum of open water is in agreement with that reported by Allison and others (1993) and Brandt and others (2005), and with broadband measurements from other studies (Briegleb and Ramanathan, 1982; Pegau and Paulson, 2001).

In all nilas cases there is a decreasing trend in albedo toward the $\mathrm{nIR}$ where ice becomes more absorptive. As nilas thickens, the albedo increases in the UV and visible wavelength regions because increased scattering in the ice prevents some radiation from penetrating through the ice to be absorbed in the underlying water. In the nIR, nilas is an optically thick medium because ice is strongly absorbing at those wavelengths; the albedo is therefore determined not by ice thickness but rather by the SSA, which is probably similar for all the nilas cases examined.

The exception to this general pattern is the albedo spectrum for the thinnest nilas sample, just $0.5-0.8 \mathrm{~cm}$ thick. It has an intermediate albedo in the UV and visible, but higher albedo than the other cases in the nIR. The nIR albedo spectrum for $3-6 \mathrm{~cm}$ nilas is similar to that of open water, and it appears that the $2.2 \mathrm{~cm}$ and $2.2-3 \mathrm{~cm}$ nilas would also be similar; however, measurements of those spectra do not extend beyond $\lambda=1060 \mathrm{~nm}$. A possible explanation for the unusual albedo spectrum of thin nilas is that the down-looking measurement could contain a significant contribution from the snow walls of the lead.

To determine the potential contribution of snow to the nilas spectrum, we produced hypothetical albedo spectra as linear combinations of the spectrum of snow and the spectrum of water, varying their relative contributions. The best match was obtained with snow occupying $9 \%$ of the downward-looking hemispheric field of view. The match was not perfect at all wavelengths, but this exercise does

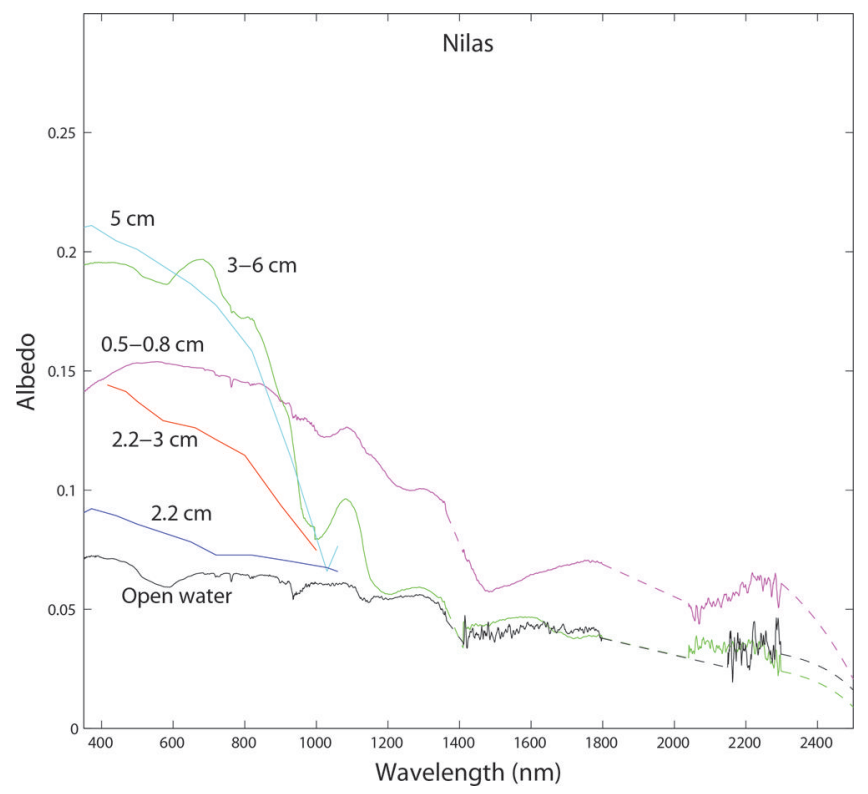

Fig. 6. Albedo spectra measured during SIPEX II for nilas and open water for wavelengths $350-2500 \mathrm{~nm}$, along with albedo spectra for nilas from previous expeditions for wavelengths $350-1060 \mathrm{~nm}$. The nilas of thickness 3-6 cm was measured on 13 October 2012, the nilas of thickness $0.5-0.8 \mathrm{~cm}$ was measured on 6 October 2012, and open water was measured on 24 October 2012. The $5 \mathrm{~cm}$ thick nilas, $2.2-3 \mathrm{~cm}$ nilas and $2.2 \mathrm{~cm}$ nilas were measured during earlier voyages and reported by Brandt and others (2005).

suggest that we should ignore the $0.5-0.8 \mathrm{~cm}$ spectrum shown in Figure 6 as not being representative of nilas because it was contaminated with snow at the margins of the scene.

There is also a possible slight contamination of the 3-6 cm thick nilas albedo spectrum. There are some bumps in the spectrum from 400 to $800 \mathrm{~nm}$ that are not seen in any of the other nilas spectra. We measured this spectrum from the side of an IRB, which was red. The cosine collector likely measured some of the reflected light from the side of the IRB. This contamination is small compared to that in the $0.5-0.8 \mathrm{~cm}$ thick nilas case, so we do not exclude the $3-6 \mathrm{~cm}$ thick nilas albedo spectra from this analysis.

\subsubsection{Frost flowers}

Frost flowers (Fig. 2) grow out of a brine skim on bare sea ice when there is a temperature difference of at least $12-16 \mathrm{~K}$ between the ice surface and the air directly above the sea ice (Perovich and Richter-Menge, 1994; Rankin and others, 2002). This large temperature difference is easiest to achieve when the ice surface is warm, as is the case for thin nilas. Evaporation from the brine skim quickly deposits as frost onto small bumps on the nearby nilas surface because the air is cold. The frost flowers continue to grow as more deposition accumulates on the crystals. Frost flowers grow when wind speeds are low; otherwise the vapor released into the atmosphere can be transported away before condensing back onto the local ice surface (Perovich and Richter-Menge, 1994). Evidence that the brine skim is the major source of vapor for the frost flowers comes from comparing the nilas surface to nearby snow-covered firstyear ice. Although frost crystals did grow on the snow surface during a cold night, they were only a few $\mathrm{mm}$ in 


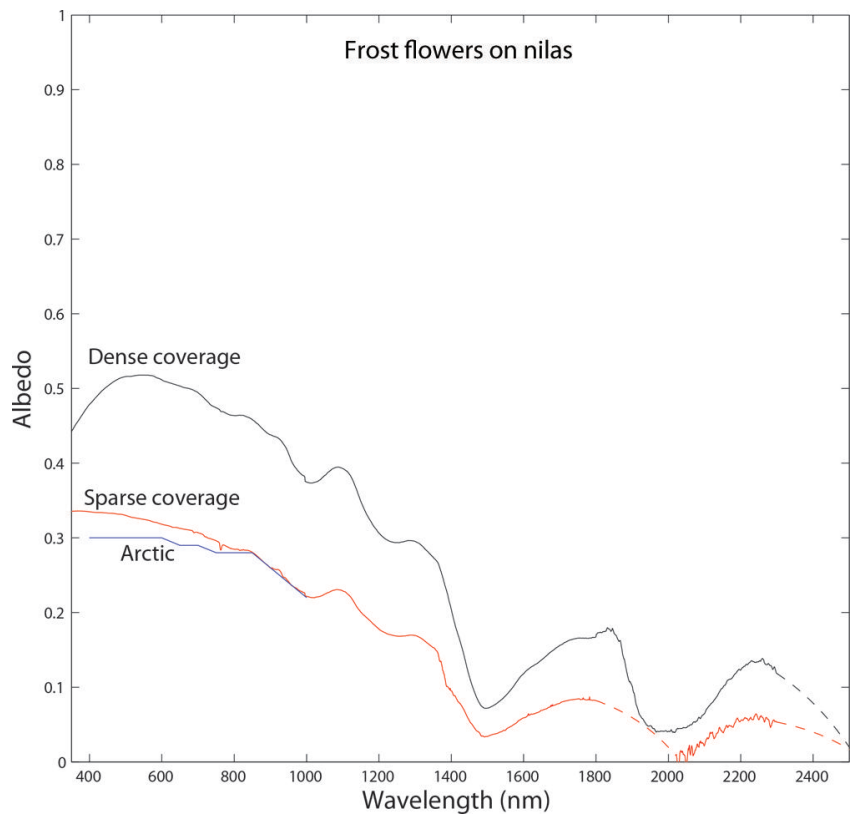

Fig. 7. Albedo spectra for frost flowers over nilas (the scenes photographed in Fig. 2). The frost flowers with dense coverage were measured on 4 October 2012 and those with sparse coverage were measured on 28 September 2012. The 'Arctic' spectrum was measured by D. Perovich (personal communication, 2014) for frost flowers with sparse coverage over $6 \mathrm{~cm}$ nilas on 3 April 1998 at the SHEBA (Surface Heat Budget of the Arctic Ocean program) site in the Beaufort Sea using a Spectron Engineering SE-590 radiometer.

height, a factor of $\sim 4$ smaller than the massive frost crystals $(1-1.5 \mathrm{~cm})$ on the nilas.

We measured frost-flower albedo on two days; on both days the frost flowers were $1-1.5 \mathrm{~cm}$ in height, but the nilas on 4 October was more densely coated than on 28 September (Fig. 2). The albedos are shown in Figure 7; comparison to Figure 6 shows that the growth of frost flowers had caused the albedo of nilas to increase by $0.2-0.3$ at visible wavelengths.

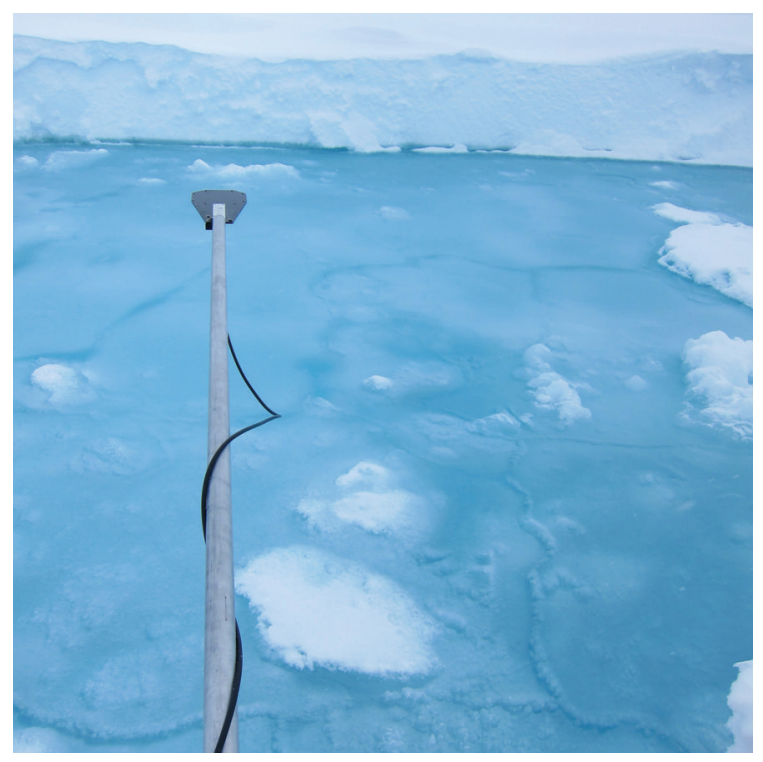

Fig. 8. Photograph of slush of thickness $18 \mathrm{~cm}$ in a narrow lead on 23 October 2012. The albedo spectrum for this scene is shown in Figure 9.

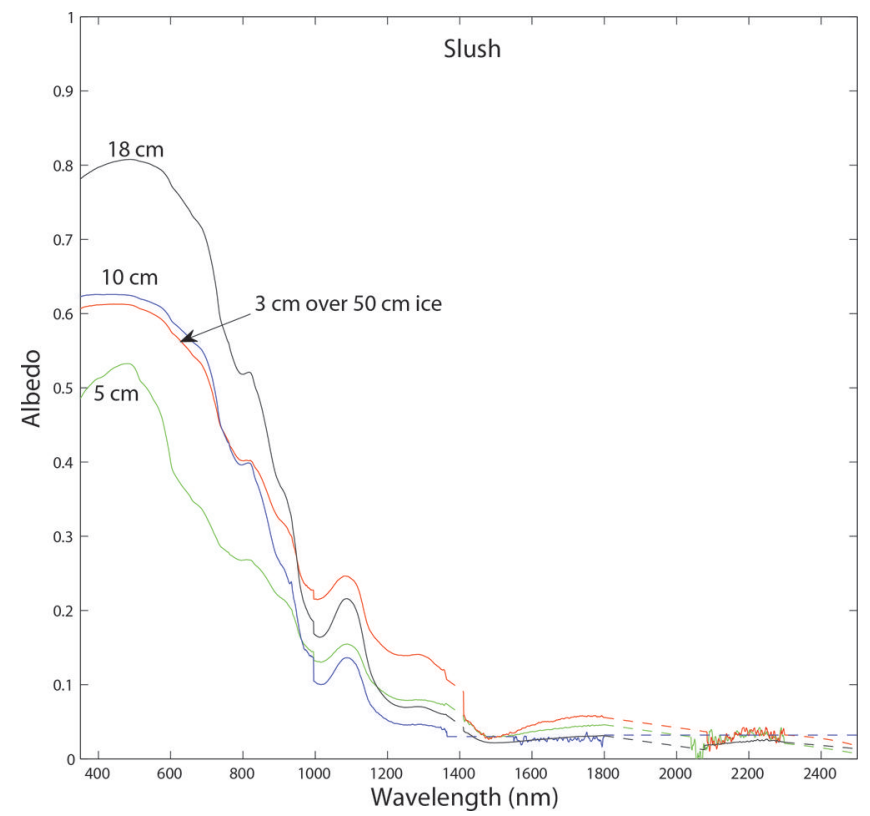

Fig. 9. Albedo spectra for slush of several thicknesses. The slush of $18 \mathrm{~cm}$ thickness was measured on 23 October, the slush of $10 \mathrm{~cm}$ thickness was measured on 20 October, the slush of $3 \mathrm{~cm}$ thickness over $50 \mathrm{~cm}$ ice was measured on 14 October and the slush of $5 \mathrm{~cm}$ thickness was measured on 9 October.

The dense frost flowers have a higher albedo than the sparse frost flowers by a factor of 1.5 in the UV and visible and a factor of 1.7 in the nIR. Both of the frost spectra have a closer resemblance in shape to the albedo spectra of snow than to open water and nilas. The frost-flower and snow albedo spectra have distinctive peaks at $1050 \mathrm{~nm}, 1800 \mathrm{~nm}$ and $2250 \mathrm{~nm}$, but these peaks are muted in the nilas and openwater spectra. Frost flowers also grow on Arctic sea ice; in Figure 7 we include a spectrum measured in the Arctic springtime by D. Perovich (personal communication, 2014).

In summary, the growth of frost flowers on nilas dramatically increases the albedo at all wavelengths, resembling a thin snow cover.

\subsubsection{Slush}

Slush (Fig. 8) is formed when snow is blown into a new lead of open water. For pure slush, Figure 9 shows that the UV and visible albedos generally increase with increasing slush thickness because increased scattering reduces the flux of radiation reaching the underlying ocean, but the shape of the albedo spectrum remains similar. In the $n I R$, slush is optically thick, so there the albedo is determined more by SSA than by thickness.

Figure 9 also displays a spectrum of $3 \mathrm{~cm}$ slush over $50 \mathrm{~cm}$ ice. This slush was formed in a different manner than the 'pure slush' cases; ice of $50 \mathrm{~cm}$ thickness floats with its surface above sea level, so snow falling onto it would not be expected to mix with sea water. We accessed this slushcovered ice floe by IRB in the wake of the ship; it is likely that turbulence caused by the ship's propellers had splashed sea water up onto the floe, wetting the snow. At UV and visible wavelengths the albedo of this surface closely resembles the spectrum of $10 \mathrm{~cm}$ slush, but in the nIR the slush-on-ice has higher albedo, indicating larger SSA. The likely cause of the larger SSA (smaller $r_{\mathrm{e}}$ ) is that the snow perched on the ice platform was incompletely wetted. 


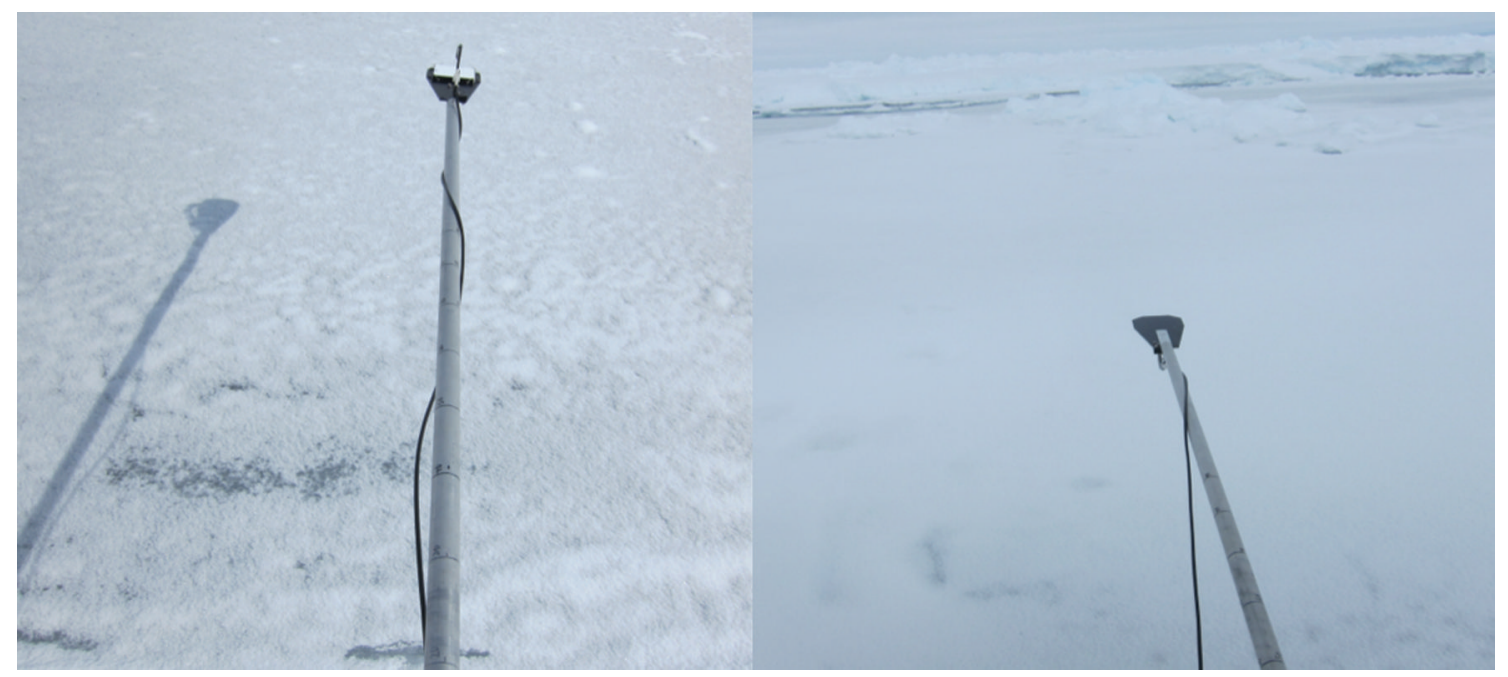

Fig. 10. Photographs of three-layer surface types taken on 2 November 2012. Left: $0.5 \mathrm{~cm}$ of snow covering $10 \mathrm{~cm}$ of slush covering $16 \mathrm{~cm}$ of ice. Right: $2 \mathrm{~cm}$ of snow covering $3 \mathrm{~cm}$ of slush covering $12 \mathrm{~cm}$ of ice. Albedos for these scenes are shown in Figure 11 .

\subsubsection{Three-layer cases}

Figure 10 shows two scenes of snow over slush over ice; their albedo spectra are plotted in Figure 11. The albedo spectra appear to be dominated by the snow: at visible wavelengths the visible albedo is much greater for the thicker snow cover but not as high as for deep snow (Fig. 4). In the nIR, where even just $0.5 \mathrm{~cm}$ of snow is nearly semiinfinite, its albedo is only slightly lower than for the $2 \mathrm{~cm}$ snow. The snow grain size is therefore probably the same in both cases, $r_{\mathrm{e}} \approx 60 \mathrm{~m}$, by comparison to figure 8 of Wiscombe and Warren (1980).

\subsection{Broadband albedos}

Following the procedures of Brandt and others (2005), we integrate the measured spectral albedos over wavelength to obtain albedos for two broad wavelength bands used in

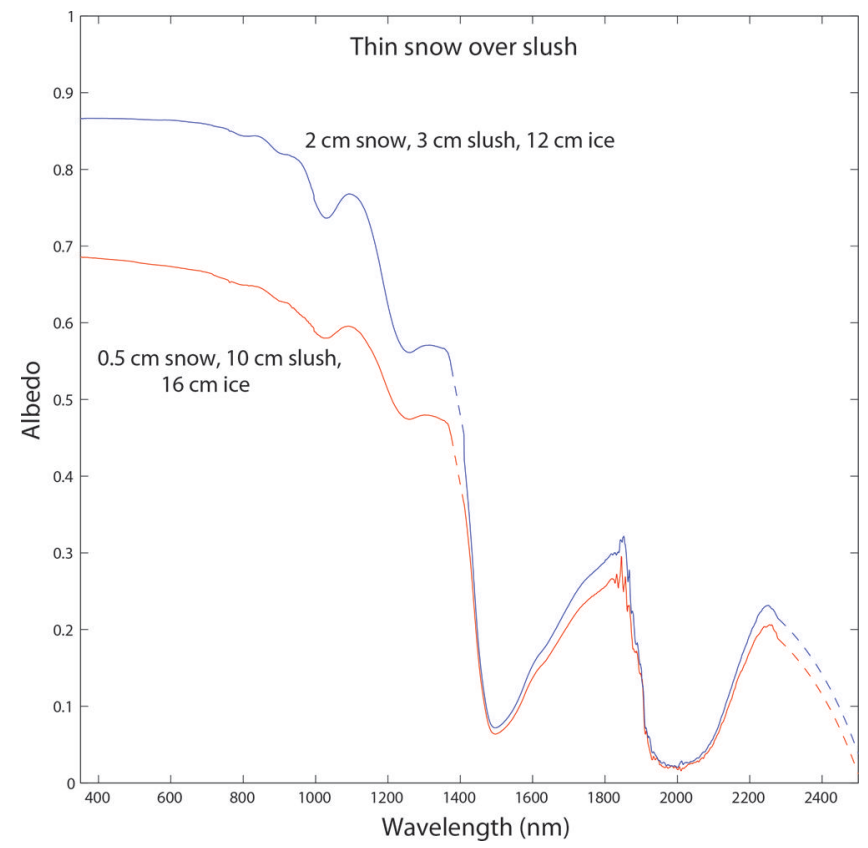

Fig. 11. Albedo spectra for the three-layer system: snow over slush over ice (scenes photographed in Fig. 10). Both spectra were measured on 2 November. climate models (290-700 nm, 700-3000 nm), as well as the average broadband albedo for the entire solar spectrum (290-3000 nm), $\alpha$ :

$$
\alpha=\frac{\int \alpha_{\lambda} F_{\lambda} \mathrm{d} \lambda}{\int F_{\lambda} \mathrm{d} \lambda}
$$

where $\alpha_{\lambda}$ is the measured spectral albedo and $F_{\lambda}$ is the downward solar spectral irradiance at wavelength $\lambda$. The broadband albedo depends on the incident solar radiation spectrum, which differs depending on whether the sky is cloudy. Here two solar spectra, one for clear-sky conditions and one for cloudy-sky conditions, characteristic of highlatitude climate during sunlit seasons are used to compute broadband albedos. We use clear and cloudy spectra that were measured at the surface of the Arctic Ocean during summer by Grenfell and Perovich (2008). The GrenfellPerovich cloudy case can be matched by specifying a cloud of visible optical depth $\tau=11$ in the atmospheric radiation model SBDART (Ricchiazzi and others, 1998); this optical depth is typical for Arctic summer stratus clouds (Tsay and Jayaweera, 1984).

For the broadband solar albedo, the limits of integration in Eqn (2) are $290 \mathrm{~nm}$ and $3000 \mathrm{~nm}$, which exceed the spectral range of our measurements, so (following Brandt and others, 2005) we assume that the UV albedo for 290$350 \mathrm{~nm}$ is the same as the albedo measured at $350 \mathrm{~nm}$, and that the nIR albedo for $2500-3000 \mathrm{~nm}$ is the same as the albedo measured at $2500 \mathrm{~nm}$. The UV assumption is reasonable because ice is nearly non-absorptive in the near-UV and the scattering is independent of wavelength in the visible and UV. The albedo at $2500 \mathrm{~nm}$ is near zero for all ice types, and there is little solar flux for $\lambda>2500 \mathrm{~nm}$, so little error can result from assuming a constant albedo for $\lambda>2500 \mathrm{~nm}$. The amount of radiation in the wavelength bands that we have extrapolated over is small: $<4 \%$ of the total solar radiation is contained in the $290-350 \mathrm{~nm}$ wavelength band and $<0.1 \%$ of the total solar radiation is contained in the 2500-3000 nm wavelength band.

Table 1 lists the broadband albedos for each surface type observed during SIPEX II. The values, particularly for the nIR, are higher under cloudy sky. As mentioned above, clouds absorb nIR radiation at wavelengths where snow and ice are also absorptive. Radiation that has passed through a cloud is 
therefore depleted in the wavelengths for which snow and ice have low albedo, so the spectrally averaged albedo is higher under cloudy-sky conditions than under clear-sky conditions (Warren, 1982). In general, the cloudy-sky albedo is more relevant in the Antarctic sea-ice zone because the average cloud cover in spring and summer exceeds $80 \%$ (Warren and others, 1988).

The only surface types measured during both SIPEX II and previous ANARE expeditions were open water, nilas and snow-covered thick first-year ice, and their broadband albedos are close to the broadband albedos for those ice types reported by Brandt and others (2005). For this reason, and because on SIPEX II we did not have the opportunity to measure the other ice types reported in tables 1 and 3 of Brandt and others (2005), we see no need to revise the albedos reported in Brandt and others (2005).

\section{LIGHT-ABSORBING IMPURITIES IN SNOW}

\subsection{Method}

Vertical profiles of LAI and density in the snowpack were obtained at five ice stations. Established methods described by Doherty and others (2010) were used to quantify the LAI, and some of the following description of the method is taken from that paper. Snow pits were dug upwind of the ship. Facing upwind and wearing clean, dust-free disposable overgloves, we used a stainless-steel spatula to put snow into plastic bags which could each hold $\sim 1 \mathrm{~kg}$ of snow. Sample sizes of 1-11 kg were collected to obtain filter loadings in the range suitable for accurate spectrophotometric measurements. Duplicate samples were typically collected at vertical intervals of $5-10 \mathrm{~cm}$. The top $2 \mathrm{~cm}$ of snow was also collected at each snow pit. Additionally, if there was obvious layering (e.g. a thin top layer of newly fallen snow or drift snow), that layer was collected separately, however thin.

The snow was kept frozen until ready for processing in a laboratory aboard the Aurora Australis. The snow from each bag was spooned into a clean glass beaker and melted in a microwave oven. The meltwater was passed through a $0.4 \mathrm{~m}$ Nuclepore filter, using a handpump to create a partial vacuum, and the volume of filtrate was measured. The melting of one bag of snow typically required 5-10 min, and the filtration another $10-20 \mathrm{~min}$. This procedure is designed to minimize the time that meltwater is in contact with glass or plastic, because soot is often hydrophobic and some could be lost to the container walls instead of collected on the filter. Another reason for keeping the snow frozen until it is ready for processing is to avoid algal growth, since algae can change the water chemistry as well as absorbing light themselves.

The transmittance spectrum of each filter was measured in an integrating-sandwich spectrophotometer that was built for this purpose in our laboratory at the University of Washington. This incorporates an integrating sphere as one side of the sandwich (Grenfell and others, 2011). The integrating-sandwich configuration is designed to minimize the effect of scattering by the aerosols on the filter, so that the measured signal is a function only of the losses due to light absorption. A set of standard filters containing known (weighed) amounts of BC in the form of a commercial soot is used to calibrate the system. The spectral shape of the absorption is used to separate BC from non-BC absorbers by the method of Grenfell and others (2011), making use of the enhanced absorption at blue and UV wavelengths by brown carbon and mineral dust.

The spectral shape is characterized by the slope of absorption on a log-log plot across the wavelength domain $450-600 \mathrm{~nm}$, where the spectrophotometer has good accuracy:

$$
\frac{\tau_{600}}{\tau_{450}}=\left(\frac{\lambda_{600}}{\lambda_{450}}\right)^{-\AA}
$$

where $\tau_{i}$ is the absorption optical depth on the filter at wavelength $\lambda_{i}$ and $\AA$ is called the absorption Ångström exponent. The separation of contributions by $\mathrm{BC}$ and non$\mathrm{BC}$ absorbers is done by assuming that the absorption Ångström exponent for $\mathrm{BC}$ is 1.0 and for non-BC lightabsorbing aerosol is 5.0. The absorption spectra are then integrated over wavelength, weighted by the incident solar spectrum for $\lambda<700 \mathrm{~nm}$ (the wavelength region where snow albedo is sensitive to impurities) to obtain the fraction of solar absorption by BC and by non-BC impurities (Doherty and others, 2010; Grenfell and others, 2011).

\subsection{Results}

Table 3 describes the snow properties at each site. Snow was collected at ice stations 1-4 and 7. We did not sample at ice stations 5, 6 and 8 because these stations were only a short distance from others we had already sampled. Samples of size $\sim 1 \mathrm{~kg}$ were collected at ice station 1 . The filters were visually blank, so at ice stations 2 and 3 larger samples of size $2-4 \mathrm{~kg}$ were collected. The filters were still nearly blank, so at ice stations 4 and 7 larger samples of size $8-11 \mathrm{~kg}$ were collected; these do show a slight darkening visible by eye.

Table 3 gives the absorption Angström exponent, the estimated $\mathrm{BC}$ mixing ratio, and the fraction of absorption due to non-BC constituents. Because the Ångström exponent for non- $B C$ is variable, causing uncertainty in the $B C /$ non- $B C$ apportionment, we also list a quantity called 'max $B C^{\prime}$. This is the maximum possible $\mathrm{BC}$, under the assumption that all the absorption at $650-700 \mathrm{~nm}$ is caused by BC. The choice of $650-700 \mathrm{~nm}$ for this assessment is due to the fact that non-BC constituents absorb only weakly in this spectral region.

There is little difference among the sites. The BC amounts are very low, $0.1-0.5 \mathrm{ngg}^{-1}$, similar to values we found previously on the East Antarctic plateau (Warren and Clarke, 1990; Grenfell and others, 1994; Warren and others, 2006). A median vertical profile of $B C$, combining results from five sites, is shown in Figure 12. The top (springtime) layers tend to have higher $\mathrm{BC}$ mixing ratios than the lower (wintertime) layers. The fraction of particulate absorption due to non-BC is $\sim 40 \%$, similar to values found in the Arctic (Doherty and others, 2010). In the Arctic the non-BC could be organic matter from combustion, vegetation, or mineral dust containing iron oxides. In the Antarctic Ocean it may largely be particulate organic matter from the ocean water and from animals (seals and penguins) occupying the surface of first-year ice.

These values are at the extreme low end of the range of $\mathrm{BC}$ mixing ratios found in natural snow, which span four orders of magnitude: $100-1200 \mathrm{ngg}^{-1}$ in northeast China (Wang and others, 2013), 30-40 ng g $^{-1}$ in Arctic Russia, 10$15 \mathrm{ng} \mathrm{g}^{-1}$ in Canada, 2-5 ng g ${ }^{-1}$ in Greenland, $4-16 \mathrm{ng} \mathrm{g}^{-1}$ in snow covering Arctic sea ice (Doherty and others, 2010, table 2) and 0.1-0.7 $\mathrm{ng} \mathrm{g}^{-1}$ in Antarctica. Of course it is not surprising that the Antarctic region has the cleanest snow on Earth. 
Table 3. The location, date (local time) and snow properties for each ice station where snow on first-year sea ice was collected for impurity analysis. Median values are given for the absorption Ångström exponent $(\AA)$, estimated fraction of absorption due to non-black carbon (nonBC) material for wavelengths $350-700 \mathrm{~nm}$, maximum possible black carbon mixing ratio, if all the absorption at $650-700 \mathrm{~nm}$ is due to black carbon (maxBC), and our best estimate of the black carbon mixing ratio (estBC)

\begin{tabular}{|c|c|c|c|c|c|c|c|}
\hline \multirow{2}{*}{$\begin{array}{l}\text { Ice station } \\
\text { No. }\end{array}$} & \multirow[t]{2}{*}{ Location } & \multirow[t]{2}{*}{ Date (2012) } & \multirow[t]{2}{*}{ Description } & \multirow[t]{2}{*}{$\AA$} & \multirow{2}{*}{$\begin{array}{c}\text { nonBC } \\
\%\end{array}$} & \multirow{2}{*}{$\begin{array}{l}\operatorname{maxBC} \\
\mathrm{ng} \mathrm{g}^{-1}\end{array}$} & \multirow{2}{*}{$\begin{array}{l}\text { estBC } \\
\mathrm{ngg}^{-1}\end{array}$} \\
\hline & & & & & & & \\
\hline 1 & $63.9^{\circ} \mathrm{S}, 119.9^{\circ} \mathrm{E}$ & 25 Sept & $0-22 \mathrm{~cm}$ : dry snow; $22-38 \mathrm{~cm}$ : slush & $1.8 \pm 0.1$ & $33 \pm 5$ & $0.5 \pm 0.2$ & $0.4 \pm 0.1$ \\
\hline 2 & $64.4^{\circ} \mathrm{S}, 120.1^{\circ} \mathrm{E}$ & 28 Sept & $\begin{array}{l}0-1 \mathrm{~cm} \text { : new snow; } 1-25 \mathrm{~cm} \text { : hard, } \\
\text { wind-packed snow }\end{array}$ & $1.8 \pm 0.1$ & $33 \pm 3$ & $0.4 \pm 0.5$ & $0.3 \pm 0.4$ \\
\hline 3 & $65.0^{\circ} \mathrm{S}, 121.0^{\circ} \mathrm{E}$ & 3-4 Oct & $\begin{array}{c}0-4 \mathrm{~cm} \text { : new snow; } 4-43 \mathrm{~cm} \text { : hard, } \\
\text { wind-packed snow; } 43-60 \mathrm{~cm} \text { : depth } \\
\text { hoar }\end{array}$ & $2.2 \pm 0.3$ & $42 \pm 7$ & $0.4 \pm 0.1$ & $0.3 \pm 0.1$ \\
\hline 4 & $65.1^{\circ} \mathrm{S}, 120.4^{\circ} \mathrm{E}$ & 8 Oct & $\begin{array}{c}0-0.2 \mathrm{~cm} \text { : hard crust; } 0.2-44 \mathrm{~cm} \text { : hard, } \\
\text { wind-packed snow }\end{array}$ & $1.9 \pm 0.4$ & $36 \pm 10$ & $0.3 \pm 0.2$ & $0.3 \pm 0.2$ \\
\hline 7 & $65.2^{\circ} \mathrm{S}, 118.6^{\circ} \mathrm{E}$ & 20 Oct & $\begin{array}{c}\text { 0-61 cm: hard wind-packed snow; } \\
61-76 \mathrm{~cm} \text { : depth hoar }\end{array}$ & $2.3 \pm 0.4$ & $45 \pm 10$ & $0.3 \pm 0.1$ & $0.2 \pm 0.1$ \\
\hline \multicolumn{4}{|c|}{ Median of all sites } & $2.0 \pm 0.4$ & $38 \pm 9$ & $0.4 \pm 0.3$ & $0.3 \pm 0.2$ \\
\hline
\end{tabular}

\section{CONCLUSIONS}

The East Antarctic sea-ice zone contains a variety of surface types with broadband solar albedos ranging from 0.06 to 0.87 . In the UV and visible wavelength regions, the albedo is most sensitive to ice thickness or snow thickness; thicker ice results in higher albedos. In the nIR wavelength region, the albedo is mainly determined by the SSA (or equivalently, the snow grain size). Just a few centimeters of snow over sea ice strongly influences the albedo spectrum. Thick snowcovered first-year ice was the most common sea-ice type encountered during this voyage, in agreement with the climatology of Brandt and others (2005). The spectral albedo of thick snow on first-year sea ice measured in this study is solely due to the snow, in close agreement with spectral albedo measured for snow on the Antarctic plateau.

Thin nilas has albedo similar to that of open water across all wavelengths, but as the ice thickens, the albedo of nilas increases in the UV and visible wavelength ranges. The

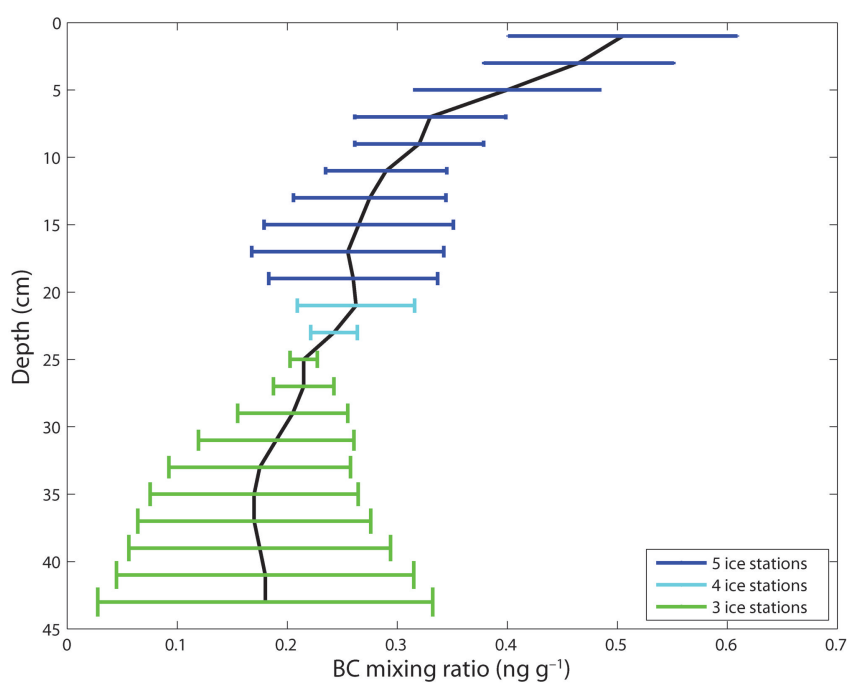

Fig. 12. Median vertical profile of estimated black carbon mixing ratio (estBC), combining results from five ice stations (when available). The legend indicates the number of ice stations used to calculate the median estBC value. growth of frost flowers on nilas causes the albedo to increase by $0.2-0.3$ and also leads to an albedo spectrum more similar in shape to that of snow than to that of open water. The frost-flower and snow albedo spectra have distinctive peaks at $1050 \mathrm{~nm}, 1800 \mathrm{~nm}$ and $2250 \mathrm{~nm}$, but these peaks are muted in the nilas and open-water spectra. The albedo of slush increases with increasing slush thickness and has an albedo spectrum similar to snow and frost flowers in the UV and visible, but similar to nilas in the nIR. The albedo of ice covered by both slush and snow is influenced by the overlying snow; however, snow cover less than $2 \mathrm{~cm}$ is not thick enough to prevent the underlying layers from influencing the albedo.

For the ice types measured in both this SIPEX voyage and our earlier voyages, the broadband albedos are in agreement (Table 1), thus validating the extrapolations into the infrared that were required in the earlier work with a smaller spectral range from the radiometers. The new types measured on this voyage, which had not been measured on earlier voyages, are frost flowers and slush.

Light-absorbing impurities are present in the snow at very low levels, comparable to values found on the East Antarctic plateau and far too low to affect the albedo. The estimated BC mixing ratios are $0.1-0.5 \mathrm{ng}$ of carbon per gram of snow, and $\sim 40 \%$ of the light absorption by impurities is caused by non-BC constituents (organic carbon and/or iron species).

\section{ACKNOWLEDGEMENTS}

We thank Tony Worby for initially sponsoring our participation in SIPEX II, and Andy Cianchi and Klaus Meiners for their friendly support as Voyage Leader and Chief Scientist, respectively. The crew of Aurora Australis, under Captain Murray Doyle, were helpful in many ways, particularly in the launching and operation of the IRB. Chris Gallagher, the Field Training Officer, kept us on-belay and otherwise attended to our safety during our measurements on thin ice. Friendly interactions with other researchers from many nations on the voyage were much appreciated. Rich Brandt, Bonnie Light and Peter Mullen provided training on operation of the ASD spectral radiometer in advance of the expedition. Rich Brandt wrote the data-processing programs for spectral albedo. 
Sarah Doherty, Tom Grenfell and Cheng Dang provided instruction on operation of the laboratory spectrophotometer for analysis of light-absorbing impurities. We benefited from discussions about ice types with Rob Massom, Rich Brandt and Tom Grenfell. Don Perovich provided the albedo spectrum of Arctic frost flowers. The research was supported by the Australian Antarctic Division and by grant ANT1141275 from the US National Science Foundation.

\section{REFERENCES}

Allison I, Brandt RE and Warren SG (1993) East Antarctic sea ice: albedo, thickness distribution, and snow cover. J. Geophys. Res., 98(C7), 12 417-12429 (doi: 10.1029/93JC00648)

Brandt RE, Warren SG, Worby AP and Grenfell TC (2005) Surface albedo of the Antarctic sea ice zone. J. Climate, 18(17), 3606-3622 (doi: 10.1175/JCLI3489.1)

Brandt RE, Warren SG and Clarke AD (2011) A controlled snowmaking experiment testing the relation between black carbon content and reduction of snow albedo. J. Geophys. Res., 116(D8), D08109 (doi: 10.1029/2010JD015330)

Briegleb B and Ramanathan V (1982) Spectral and diurnal variations in clear sky planetary albedo. J. Appl. Meteorol., 21(8), 1160-1171 (doi:10.1175/1520-0450(1982)021<1160: SADVIC $>2.0 . \mathrm{CO} ; 2)$

Clarke AD and Noone KJ (1985) Soot in the Arctic snowpack: a cause for perturbations in radiative transfer. Atmos. Environ., 19(12), 2045-2053 (doi: 10.1016/j.atmosenv.2007.10.059)

Doherty S, Warren SG, Grenfell TC, Clarke AD and Brandt RE (2010) Light-absorbing impurities in Arctic snow. Atmos. Chem. Phys., 10(23), 11647-11680 (doi: 10.5194/acp-1011647-2010)

Fitzpatrick MF and Warren SG (2005) Transmission of solar radiation by clouds over snow and ice surfaces. Part II: Cloud optical depth and shortwave radiative forcing from pyranometer measurements in the Southern Ocean. J. Climate, 18(22), 4637-4648 (doi: 10.1175/JCLI3562.1)

Fitzpatrick MF and Warren SG (2007) The relative importance of clouds and sea ice for the solar energy budget of the Southern Ocean. J. Climate, 20(6), 941-954 (doi: 10.1175/JCLI4040.1)

Fitzpatrick MF, Brandt RE and Warren SG (2004) Transmission of solar radiation by clouds over snow and ice surfaces: a parameterization in terms of optical depth, solar zenith angle, and surface albedo. J. Climate, 17(2), 266-275 (doi: 10.1175/ 1520-0442(2004)017<0266:TOSRBC>2.0.CO;2)

France JL and 9 others (2012) Hydroxyl radical and NOx production rates, black carbon concentrations and light-absorbing impurities in snow from field measurements of light penetration and nadir reflectivity of onshore and offshore coastal Alaskan snow. J. Geophys. Res., 117(D14), D00R12 (doi: 10.1029/2011JD016639)

Grenfell TC and Perovich DK (2008) Incident spectral irradiance in the Arctic Basin during the summer and fall. J. Geophys. Res., 113(D12), D12117 (doi: 10.1029/2007JD009418)

Grenfell TC and Warren SG (1999) Representation of a nonspherical ice particle by a collection of independent spheres for scattering and absorption of radiation. J. Geophys. Res., 104(D24), 31 697-31 709 (doi: 10.1029/2005JD005811)

Grenfell TC, Warren SG and Mullen PC (1994) Reflection of solar radiation by the Antarctic snow surface at ultraviolet, visible, and near-infrared wavelengths. J. Geophys. Res., 99(D9), 18669-18684 (doi: 10.1029/94JD01484)

Grenfell TC, Doherty SJ, Clarke AD and Warren SG (2011) Light absorption from particulate impurities in snow and ice determined by spectrophotometric analysis of filters. Appl. Opt., 50(14), 2037-2048 (doi: 10.1364/AO.50.002037)

Hall A (2004) The role of surface albedo feedback in climate. J. Climate, 17(7), 1550-1568 (doi: 10.1175/1520-0442 (2004)017<1550:TROSAF>2.0.CO;2)
Hoffer A and 7 others (2006) Optical properties of humic-like substances (HULIS) in biomass-burning aerosols. Atmos. Chem. Phys., 6(11), 3563-3570 (doi: 10.5194/acp-6-3563-2006)

Holland MM and Bitz CM (2003) Polar amplification of climate change in coupled models. Climate Dyn., 21(3), 221-232 (doi: 10.1007/s00382-003-0332-6)

Holland MM, Bitz CM and Weaver AJ (2001) The influence of sea ice physics on simulations of climate change. J. Geophys. Res., 106(C9), 19 639-19655 (doi: 10.1029/2000JC000651)

Horner R and 9 others (1992) Ecology of sea ice biota. 1. Habitat, terminology, and methodology. Polar Biol., 12(3-4), 417-427 (doi: 10.1007/BF00243113)

Hudson SR, Warren SG, Brandt RE, Grenfell TC and Six D (2006) Spectral bidirectional reflectance of Antarctic snow: measurements and parameterization. J. Geophys. Res., 111(D18), D18106 (doi: 10.1029/2006JD007290)

Kindel BC, Qu Z and Goetz AFH (2001) Direct solar spectral irradiance and transmittance measurements from 350 to 2500 nm. Appl. Opt., 40(21), 3483-3494 (doi: 10.1364/ AO.40.003483)

Massom RA and 12 others (2001) Snow on Antarctic sea ice. Rev. Geophys., 39(3), 413-445 (doi: 10.1029/2000RG000085)

Matzl M and Schneebeli M (2006) Measuring specific surface area of snow by near-infrared photography. J. Glaciol., 52(179), 558564 (doi: 10.3189/172756506781828412)

Matzl M and Schneebeli M (2010) Stereological measurement of the specific surface area of seasonal snow types: comparison to other methods, and implications for mm-scale vertical profiling. Cold Reg. Sci. Technol., 64(1), 1-8 (doi: 10.1016/j.coldregions. 2010.06.006)

Meehl GA and Washington WM (1990) $\mathrm{CO}_{2}$ climate sensitivity and snow-sea-ice-albedo parameterizations in an atmospheric GCM coupled to a mixed-layer ocean. Climatic Change, 16(3), 283-306 (doi: 10.1007/BF00144505)

Mironova ZF (1973) Albedo of Earth's surface and clouds. In Kondrat'ev KYa ed. Radiation characteristics of the atmosphere and the Earth's surface. Amerind, New Delhi

National Snow and Ice Data Center (NSIDC) (2012) Antarctic sea ice reaches record maximum extent. NSIDC Notes 81, 2

Pegau WS and Paulson CA (2001) The albedo of Arctic leads in summer. Ann. Glaciol., 33, 221-224 (doi: 10.3189/ 172756401781818833)

Perovich DK and Richter-Menge JA (1994) Surface characteristics of lead ice. J. Geophys. Res., 99(C8), 16341-16350 (doi: 10.1029/ 94JC01194)

Rankin AM, Wolff EW and Martin S (2002) Frost flowers: implications for tropospheric chemistry and ice core interpretation. J. Geophys. Res., 107(D23), 4683 (doi: 10.1029/ 2002JD002492)

Ricchiazzi P, Yang S, Gautier C and Sowle D (1998) SBDART: a research and teaching software tool for plane-parallel radiative transfer in the Earth's atmosphere. Bull. Am. Meteorol. Soc., 79(10), 2101-2114 (doi: 10.1175/1520-0477(1998)079<2101: SARATS $>2.0 . \mathrm{CO} ; 2)$

Rind D, Healy R, Parkinson C and Martinson D (1995) The role of sea ice in $2 \times \mathrm{CO}_{2}$ climate model sensitivity. Part I: The total influence of sea-ice thickness and extent. J. Climate, 8(3), 449-463 (doi: 10.1175/1520-0442(1995)008<0449:TROSII> 2.0.CO;2)

Rind D, Healy R, Parkinson C and Martinson D (1997) The role of sea ice in $2 \times \mathrm{CO}_{2}$ climate model sensitivity: Part II: hemispheric dependencies. Geophys. Res. Lett., 24(12), 1491-1494 (doi: 10.1029/97GL01433)

Style RW and Worster MG (2009) Frost flower formation on sea ice and lake ice. Geophys. Res. Lett., 36(11), L11501 (doi: 10.1029/ 2009GL037304)

Toyota T, Massom R, Tateyama K, Tamura T and Fraser A (2011) Properties of snow overlying the sea ice off East Antarctica in late winter, 2007. Deep-Sea Res. II, 58(9-10), 1137-1148 (doi: 10.1016/j.dsr2.2010.12.002) 
Tsay SC and Jayaweera K (1984) Physical characteristics of Arctic stratus clouds. J. Climate Appl. Meteorol., 23(4), 584-596 (doi: 10.1175/1520-0450(1984)023<0584:PCOASC >2.0.CO;2)

Voisin D and 9 others (2012) Carbonaceous species and humic like substances (HULIS) in Arctic snowpack during OASIS field campaign in Barrow. J. Geophys. Res., 117(D14), D00R19 (doi: 10.1029/2011JD016612)

Wang X, Doherty SJ and Huang J (2013) Black carbon and other light-absorbing impurities in snow across Northern China. J. Geophys. Res., 118(3), 1471-1492 (doi: 10.1029/ 2012JD018291)

Warren SG (1982) Optical properties of snow. Rev. Geophys., 20(1), 67-89 (doi: 10.1029/RG020i001p00067)

Warren SG and Brandt RE (2008) Optical constants of ice from the ultraviolet to the microwave: a revised compilation. J. Geophys. Res., 113(D14), D14220 (doi: 10.1029/2007JD009744)

Warren SG and Clarke AD (1990) Soot in the atmosphere and snow surface of Antarctica. J. Geophys. Res., 95(D2), 1811-1816 (doi: 10.1029/JD095iD02p01811)

Warren SG and Wiscombe WJ (1980) A model for the spectral albedo of snow. II. Snow containing atmospheric aerosols.
J. Atmos. Sci., 37(12), 2734-2745 (doi: 10.1175/15200469(1980)037<2734:AMFTSA >2.0.CO;2)

Warren SG, Hahn CJ, London J, Chervin RM and Jenne RL (1988) Global distribution of total cloud cover and cloud type amounts over the ocean. (Tech. Note NCAR/TN-317+STR) National Center for Atmospheric Research, Boulder, $\mathrm{CO}$

Warren SG, Roesler CS, Morgan VI, Brandt RE, Goodwin ID and Allison I (1993) Green icebergs formed by freezing of organicrich seawater to the base of Antarctic ice shelves. J. Geophys. Res., 98(C4), 6921-6928 (doi: 10.1029/92JC02751)

Warren SG, Brandt RE and Grenfell TC (2006) Visible and nearultraviolet absorption spectrum of ice from transmission of solar radiation into snow. Appl. Opt., 45(21), 5320-5334 (doi: 10.1364/AO.45.005320)

Wiscombe WJ and Warren SG (1980) A model for the spectral albedo of snow. I. Pure snow. J. Atmos. Sci., 37(12), 2712-2733 (doi: 10.1175/1520-0469(1980)037<2712:AMFTSA>2.0.CO;2)

Wiscombe WJ, Welch RM and Hall WD (1984) The effects of very large drops on cloud absorption. Part I. Parcel models. J. Atmos. Sci., 41(8), 1336-1355 (doi: 10.1175/15200469(1984)041<1336:TEOVLD>2.0.CO;2) 38846 